\title{
Seismic Assessment of Arch Dams Using Fragility Curves
}

\author{
Vandad Kadkhodayan ${ }^{\mathrm{a}}$, S. Meisam Aghajanzadeh ${ }^{\mathrm{b}}$, and Hasan Mirzabozorg ${ }^{\mathrm{c} *}$ \\ ${ }^{a}$ Msc Graduated student, Civil Engineering Department, K.N. Toosi University of Technology, Tehran, Iran \\ ${ }^{b}$ PHD Candidate, Civil bEngineering Department, K.N. Toosi University of Technology, Tehran, Iran \\ ${ }^{c}$ Associate Professor, Civil Engineering Department, K.N. Toosi University of Technology, Tehran, Iran
}

Received 25 November 2015; Accepted 22 December 2015

\begin{abstract}
In the present paper, the IDA approach is applied to analyzing a thin high arch dam. The parameters of Sa, PGA and PGV are used as intensity measure (IM) and the overstressed area (OSA) is utilized as engineering demand parameter (EDP) and then, three limit states are assigned to the considered structure using the IDA curves. Subsequently, fragility curves are calculated and it is showed that the PGA is a better parameter to be taken as IM. In addition, it is found that the utilizing the proposed methodology, quantifying the qualitative limit states is probable. At last, having the fragility curves and considering their slope in addition to the other routine data which can be extracted from these curves, one may be able to conclude that in what performance level the considered dam body seems to be weak and needs retrofitting works.

Keywords: Arch Dam, Fragility Curve, IDA Approach, Overstressed Area;
\end{abstract}

\section{Introduction}

Arch dams as mega structures are built to store water for various purposes like as irrigation, flood control, recreation and development of nations. If these structures fail to tolerate imposed loading, drastic human and financial losses are caused due to release of their reservoir large amount of water. Therefore, it can be deduced seismic assessment of such structures is a major challenge. There are various approaches to show safety plus practicality of arch dams.

One of the recent known methods is forming fragility curves. In general, a fragility curve indicates the corresponding performance against any random variable; whether be the ground motion acceleration or the dam water level.

Several researchers have investigated seismic performance of structures by fragility curves. Rota et al. (2010) proposed an approach to derive fragility curves for masonry buildings. They obtained analytical fragility curves for masonry buildings from some detailed series of 3D nonlinear dynamic analyses of these structures [1]. Shinozuka et al.(2001) expressed fragility curves in analytical method for Memphis bridges considering new criteria for steel yielding and concrete strength [2]. Kim and Shinozuka (2003) and Padgett and Roches (2008) surveyed the effect of retrofitting on concrete columns of bridges by fragility curves [3, 4]. Iichii (2003) developed the fragility curves for offshore walls to study their seismic performance [5]. Karim and Yamazaki (2007) developed the fragility curves for studying the effect of using base isolation to improve the behavior of columns under seismic loading [6].

Some researchers have investigated on the seismic performance of concrete dams. Ellingwood and Tekie (2001) presented quantitative methods to evaluate failure probabilities of Bluestone concrete gravity dam. In their study, several stages (limit states) of the dam behavior were investigated under progressively increasing levels of the flood [7]. In addition, Tekie and Ellingwood (2003) developed fragilities of Bluestone concrete gravity dam to evaluate its performance under seismic loading. Based on their study, sliding the dam-foundation interface and simultaneously

\footnotetext{
* Corresponding author: mirzabozorg@kntu.ac.ir
} 
tensile cracking at the dam neck is possible in maximum credible earthquake [8]. Alembagheri and Ghaemian (2013) conducted a nonlinear incremental dynamic analysis (IDA) for damage assessment of Morrow Point dam with respect to the spectral intensity of the stream component [9]. Also, Alambagheri and Ghaemian (2013) performed an IDA for recognition of the various limit states of Pine Flat dam investigating the influence of friction angle and lift joint slope. [10].

In the current paper, the IDA approach is used to consider the structural performance of a well-known high thin arch dam applying 9 sets of scaled three-component earthquakes. The Sa, PGA and PGV are used as intensity measure (IM) and over stress area (OSA) is used as the engineering demand parameter (EDP). Based on the conducted analyses, the IDA curves are obtained and three performance levels of serviceability, damage control and collapse prevention are clarified. Furthermore, the corresponding fragility curves are extracted.

\section{Numerical Modeling}

In the current study, Dez dam which a thin double curvature arch dam is chosen to study the structural performance and modeled using three-dimensional finite elements (see figure 1). The total height of the dam is $203 \mathrm{~m}$ from the base. The dam is modeled accounting the contraction and peripheral joints. By modeling of contraction and peripheral joints, the dam body nonlinear behavior is allowed. The 8-node cubic elements having translational degrees of freedom in global $\mathrm{x}, \mathrm{y}$ and $\mathrm{z}$ directions are used to model the dam body and its surrounding foundation rock extending about twice of the dam height in each direction. The length of the modeled reservoir is almost 5 times the height of the dam body. The pressure is assumed zero at the free surface of the reservoir and the boundary condition for the upstream truncated end of the reservoir are considered to absorb full hydrodynamic wave impact. For modeling the reservoir domain, fluid elements having pressure in addition to the translational degrees of freedom are utilized [11].
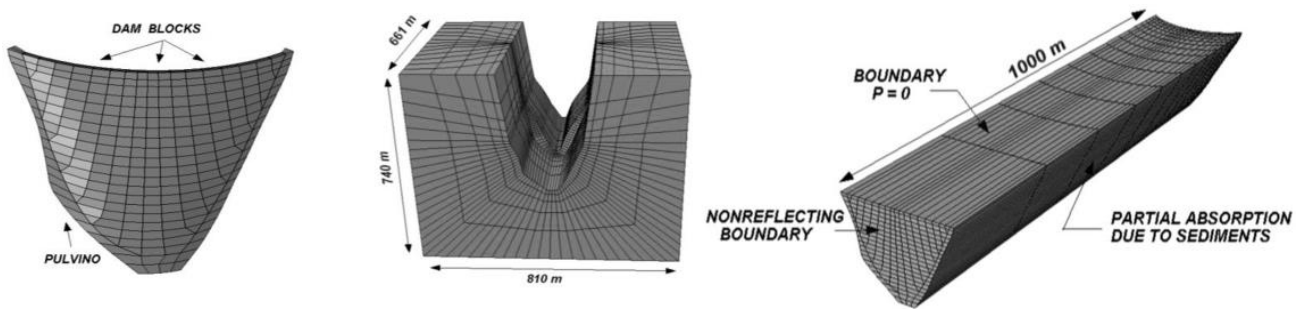

Figure 1. Finite-element mesh of dam, reservoir and foundation

The modulus of elasticity, Poisson's ratio, density, the compressive and tensile strengths and their corresponding dynamic magnification factors for the mass concrete are $40 \mathrm{GPa}, 0.2,2400 \mathrm{~kg} / \mathrm{m} 3,35 \mathrm{MPa}, 3.4 \mathrm{MPa}, 1.15$ and 1.5 respectively. The surrounding foundation rock is assumed to be massless with the Poisson's ratio taken as 0.25 . The two values of $13 \mathrm{GPa}$ and $15 \mathrm{GPa}$ are taken as the modulus of deformation in the foundation rock medium for the saturated (below the crest level of the dam body) and unsaturated parts of the foundation (above the crest level), respectively.

\section{IDA curve}

IDA curves are obtained utilizing the incremental dynamic analyses (IDA). In an IDA approach, a series of earthquake ground motions, each scaled to multiple levels of intensities are applied to the structure. Horizontal axis of an IDA curve is the damage measure indexed as DM or engineering demand parameter (EDP) showing the structural responses and the vertical axis is the intensity measure as IM showing the shaking intensity.

In this study, the three various parameters of a ground motion are used as IM, which are; Sa; PGA and PGV and the overstressed area (OSA) is utilized as EDP. For calculation of OSA, the areas experiencing the tensile stresses over $5.1 \mathrm{MPa}$, which is the static tensile strength multiplied by the corresponding dynamic magnification factor are determined. It must be mentioned that OSA is calculated separately for the downstream and upstream faces.

As mentioned previously, the provided finite element model is subjected to the 9 sets of three-component earthquake ground motions each scaled to multiple levels of intensity (see Table 1). At the lower levels of the seismic loading, the structure is in the elastic region. By incremental increase of the earthquake intensity, the dam body crosses the elastic limit and enters to the yielding stage reaching to the collapse. The structure's behavior in the elastic, yielding and collapse stages clarifies its seismic performance and therefore, the structural capacities can be identified. In the current study, the IDA curves are obtained using the 5th order polynomial shown in figures 2 to 4 . 
Table 1. Selected earthquakes

\begin{tabular}{|c|c|c|c|}
\hline No. & Earthquake name & Level & Scale factor range \\
\hline 1 & Duzce & MCL & $0.2-2.7$ \\
\hline 2 & Manjil & MCL & $0.5-2.0$ \\
\hline 3 & Tabas & MCL & $0.5-2.0$ \\
\hline 4 & Loma Prieta & MDL & $0.5-4.0$ \\
\hline 5 & Qaen 1 & MDL & $0.5-4.0$ \\
\hline 6 & Northridge & MDL & $0.5-2.4$ \\
\hline 7 & San Fernando & DBL & $0.5-4.0$ \\
\hline 8 & Northridge & DBL & $0.8-3.5$ \\
\hline 9 & Spitak & DBL & $1.0-4.0$ \\
\hline
\end{tabular}


Figure 2. IDA Curves based on Sa
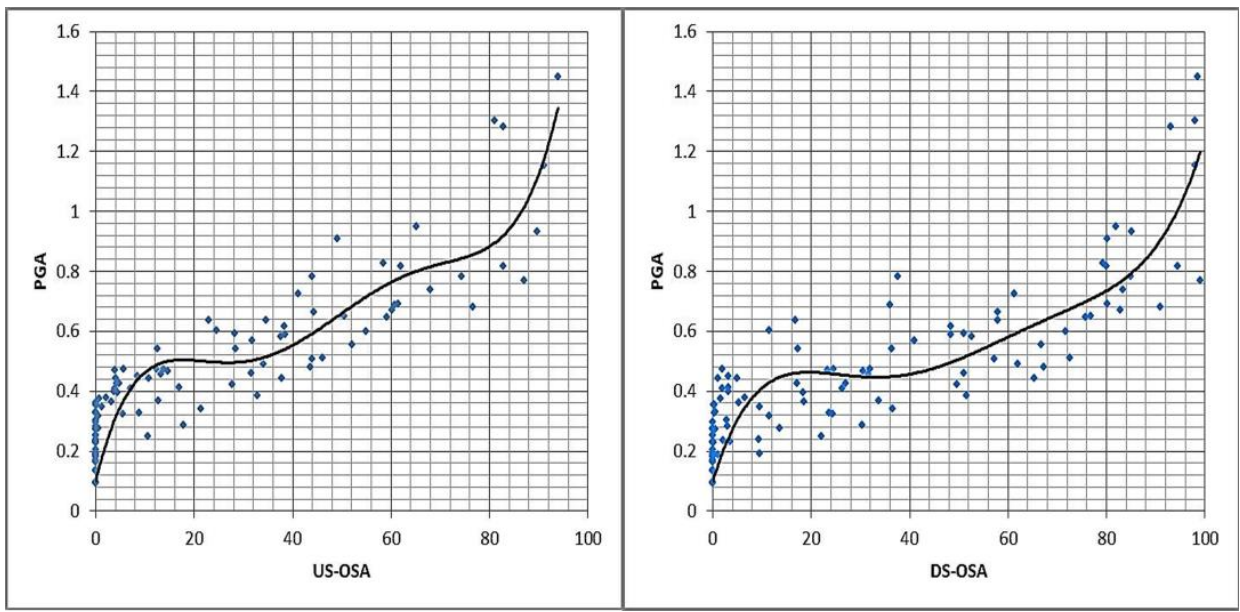

Figure 3. IDA Curves based on PGA
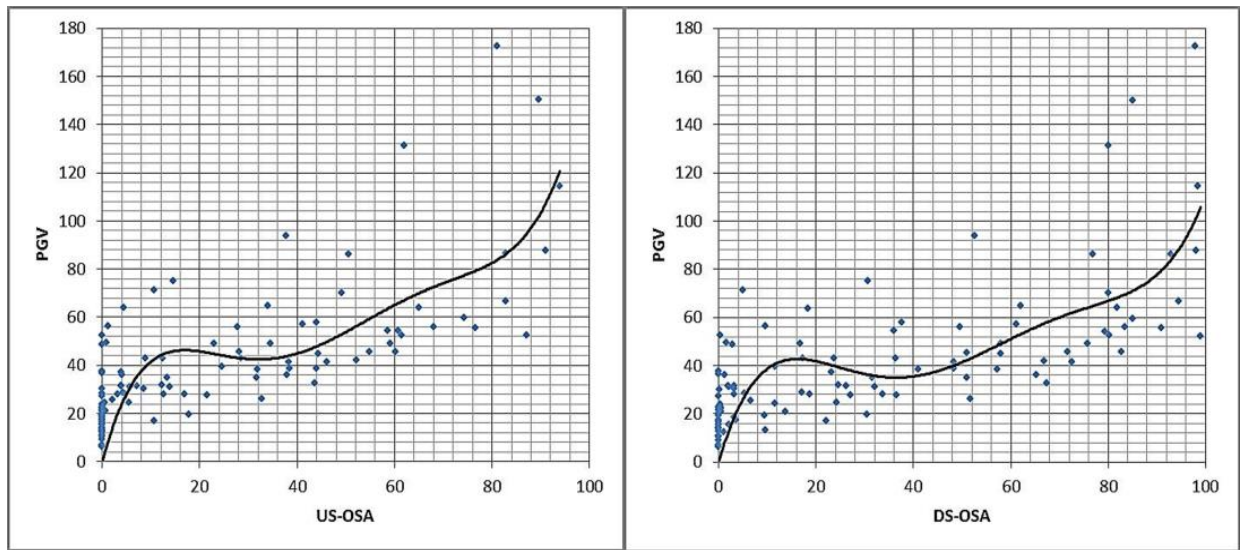

Figure 4. IDA Curves based on PGV 
As it can be seen, the three different regions are obvious and based on these regions three limit states are assigned:

I- Serviceability stage indexed as $\mathrm{S}$, in which the performance curve is linear. During this stage, the structure performs flawlessly after loading.

II- Damage control stage indexed as DC, where the performance curve is approximately horizontal. During this stage, the structure suffers small damage needing quick recovery.

III- Collapse prevention stage indexed as $\mathrm{CP}$, where the performance curve is again approximately linear with constant slope. The structure suffers structural damages tremendously due to loading threatening lives.

Based on figures 2 to 4, on the upstream face, the IDA curves are linear with constant slope until OSA=12\%. After that, the slope decreases and the IDA curve are close to horizontal. Thus, OSA $=12 \%$ can be considered as final serviceability limit state on the upstream face. Horizontal IDA curve will continue until OSA $=30 \%$. This is assigned as the final limit state for the damage control on the upstream face. After OSA $=30 \%$, the slope of the IDA curve increases and at the range of OSA $>30 \%$, the collapse prevention limit state must be investigated. On the downstream face, $\mathrm{OSA}=16 \%$ and $\mathrm{OSA}=36 \%$ are the limit states for the serviceability and damage control levels, respectively. These limit states are shown in Table 2. As it can be seen, the upstream limit states are a little lower than those obtained for the downstream face. Different OSAs on the upstream and downstream faces show that an arch dam does not behave as a shell structure.

Table 2. Performance indexes based on OSA

\begin{tabular}{|c|c|c|c|}
\cline { 2 - 4 } \multicolumn{1}{c|}{} & $\mathrm{S}$ & $\mathrm{DC}$ & $\mathrm{CP}$ \\
\hline Upstream & OSA $<12 \%$ & $12 \%<\mathrm{OSA}<30 \%$ & $30 \%<\mathrm{OSA}$ \\
\hline Downstream & OSA $<16 \%$ & $16 \%<$ OSA $<36 \%$ & $36 \%<\mathrm{OSA}$ \\
\hline
\end{tabular}

\section{Fragility Curves}

The Fragility curves are drawn utilizing the normal distribution. As known, a random variable $X$ is normal if its probability density functions $f_{x}(x)$ is given as follows [12]:

$$
f_{x}(x)=\frac{1}{\sigma \sqrt{2 \pi}} \exp \left[-\frac{(x-m)^{2}}{2 \sigma^{2}}\right],-\infty<x<+\infty
$$

Where, $\mathrm{m}$ and $\sigma$ are the mean and standard deviation, respectively and are calculated as follows [12]:

$$
\begin{aligned}
& \sigma=\sqrt{\left[\frac{1}{n-1} \sum_{i=1}^{n}\left(x_{i}-m\right)^{2}\right]} \\
& m=\frac{1}{n} \sum_{i=1}^{n} x_{i}
\end{aligned}
$$

The area covered by the probability distribution function from the beginning to a given $\mathrm{X}$ point shows the probability of X variation`s existence. Thereupon, its corresponding probability distribution function is [12]:

$$
F_{x}(x)=\frac{1}{\sigma \sqrt{2 \pi}} \int_{-\infty}^{x} \exp \left[-\frac{(u-m)^{2}}{2 \sigma^{2}}\right] d u,-\infty<x<+\infty
$$

In the current paper, Sa, PGA and PGV are chosen as random variables and their normal distribution characteristics are calculated. Results are shown in figures 5, 7 and 9. Further, fragility curves for various performance levels are calculated using equation 4 and results are shown in figures 6,8 and 10.

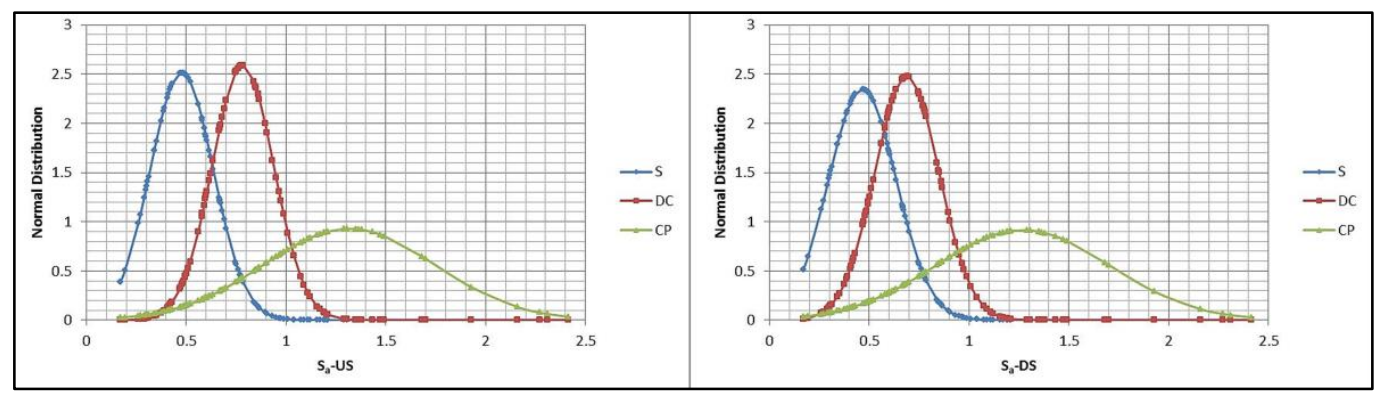

Figure 5. Normal distribution curves for different performances level based on Sa 


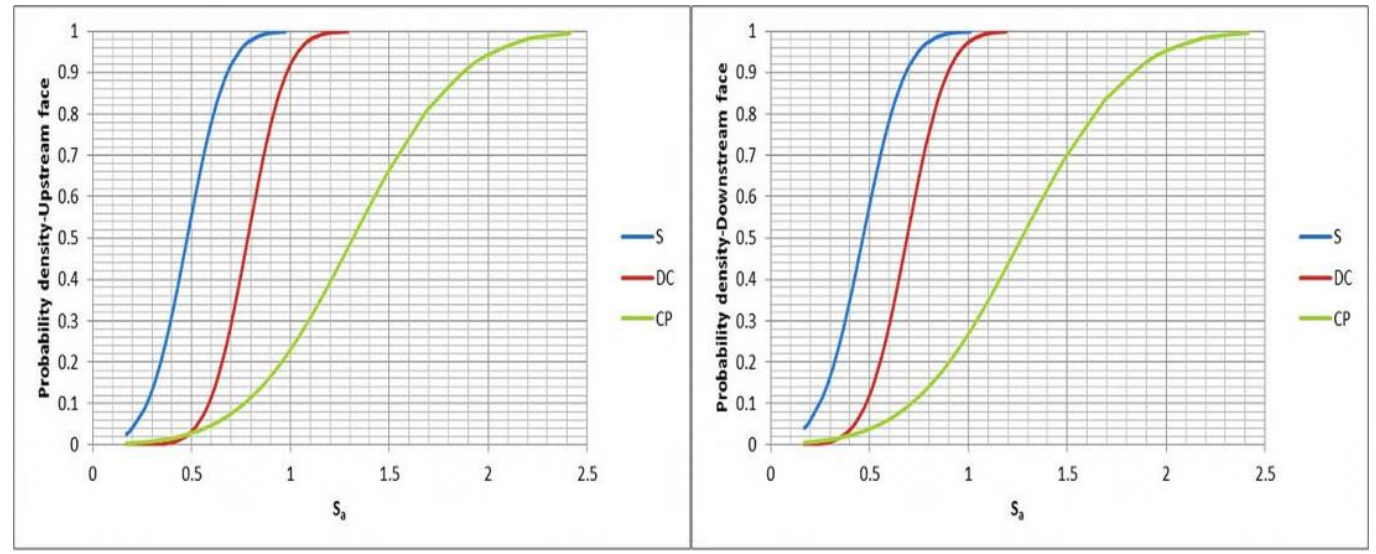

Figure 6. Fragility curves for different performance levels based on Sa

Considering figure 6, we can find that:

I. Probability of the serviceability limit state occurrence is about $100 \%$ on both the upstream and downstream faces for an earthquake with a spectral acceleration of $1 \mathrm{~g}$.

II. Probability of damage control limit state occurrence is about $100 \%$ on the upstream face for an earthquake with a spectral acceleration of $1.3 \mathrm{~g}$. But for the downstream face the spectral acceleration corresponding to this limit state is $1.2 \mathrm{~g}$.

III. Probability of the collapse prevention limit state is about $100 \%$ for an earthquake with a spectral acceleration of $2.4 \mathrm{~g}$ on both the upstream and downstream faces.

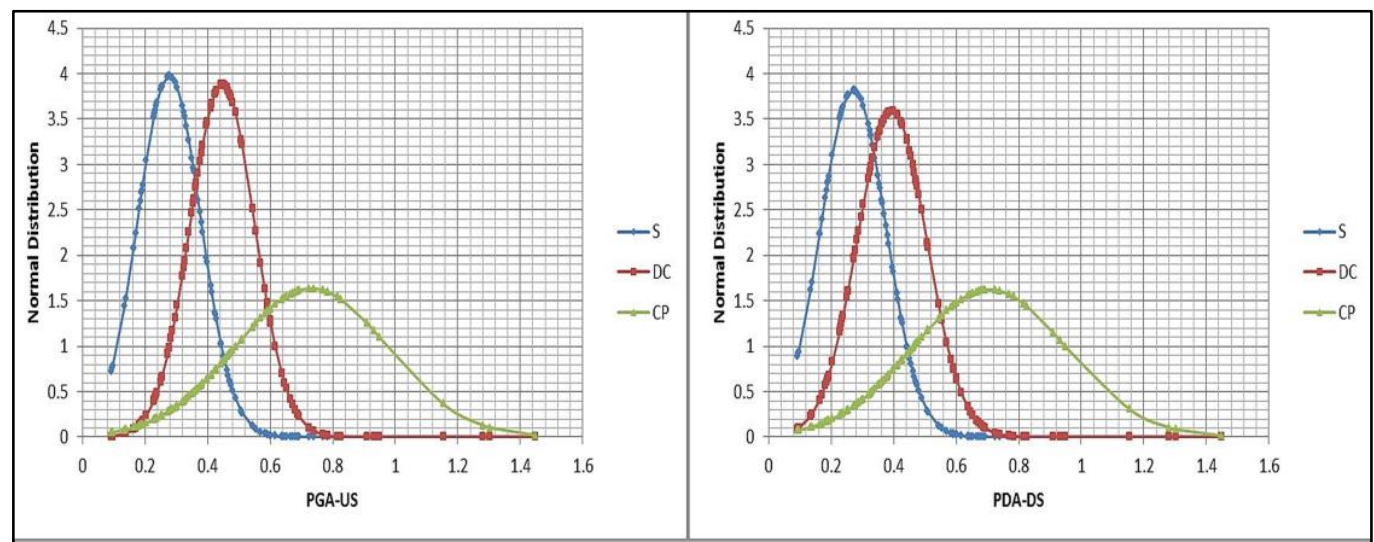

Figure 7. Normal distribution curves for different performances level based on PGA



Figure 8. Fragility curves for different performance levels based on PGA

Based on figure 8, it can be concluded that:

I. Probability of the serviceability limit state occurrence is about $100 \%$ on both the upstream and downstream faces for an earthquake with a PGA of $0.6 \mathrm{~g}$.

II. Probability of the damage control limit state occurrence is about $100 \%$ on the upstream face for an earthquake with a PGA of $0.78 \mathrm{~g}$. But for the downstream face the PGA corresponding to this limit state is $0.75 \mathrm{~g}$.

III. Probability of the collapse prevention limit state is about $100 \%$ for an earthquake with a PGA of $1.45 \mathrm{~g}$ on both the upstream and downstream faces. 


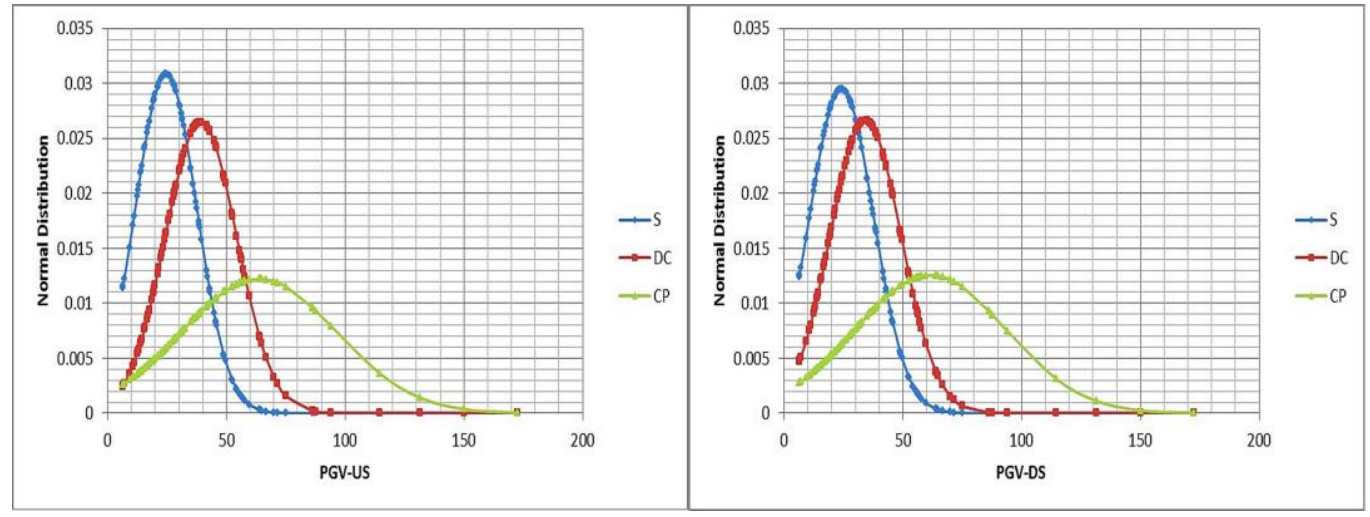

Figure 9. Normal distribution curves for different performances level based on PGV

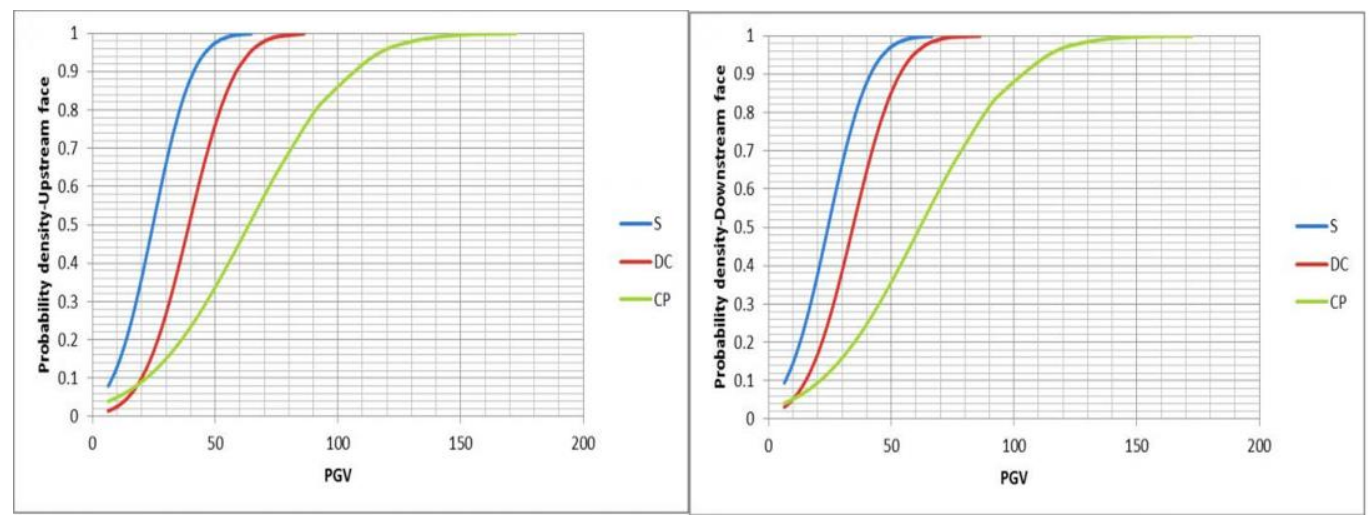

Figure 10. Fragility curves for different performance levels based on PGV

As shown in figure 10:

I. Probability of the serviceability limit state occurrence is about $100 \%$ on both the upstream and downstream faces for an earthquake with a PGV of $65 \mathrm{~m} / \mathrm{s}$.

II. Probability of the damage control limit state occurrence is about $100 \%$ on both the upstream and downstream faces for an earthquake with a PGV of $85 \mathrm{~m} / \mathrm{s}$.

III. Probability of the collapse prevention limit state is about $100 \%$ for an earthquake with a PGV of $170 \mathrm{~m} / \mathrm{s}$ at both the upstream and downstream faces.

As it can be seen in figures 5 to 10, the PGV fragility curves are a bit different from the PGA and Sa fragility curves. Furthermore, the first vibration mode of the dam changes during seismic loading. Therefore, the PGA seems to be more to form fragility curves for the considered arch dam. It is worth mentioning that at lower levels of earthquake loadings, the curves are interfered with each other (as seen in figure 10), which is due to analytical and statistical errors. These errors are lower for the curves constructed using Sa and PGA in comparison with those formed using $\mathrm{PGV}$. This matter is another reason for throwing out PGV based corves in the next sections.

\section{Conclusions}

In the present paper, the IDA approach was employed to define the quantitative structural performance limit states for a high and thin double curvature arch dam. In addition, the fragility curves were extracted considering the various IMs and a suitable EDP.

The parameters of Sa, PGA and PGV were selected as IM and overstressed area indexed as OSA was employed as EDP. It was showed that PGA is a better parameter to be taken as IM for constructing the IDA curve in studying the seismic performance of the considered arch dam. It was found that different OSAs are obtained on the upstream and downstream faces for a specified limit state and then, an arch dam cannot be modeled as a shell structure. Along that, it was observed that OSA is more critical on the upstream face.

Considering the extracted IDA curves, three limit states corresponding to the serviceability, damage control and collapse prevention performance levels were assigned to the dam body. Comparing the obtained limits states, it was clarified that the fragility curves pertinent to the serviceability and damage control performance levels are too steep and necessary treatment to increase the dam body capacity at these levels should be conducted especially on the downstream faces. 


\section{References}

[1] Rota, M., A. Penna, and G. Magenes. "A methodology for deriving analytical fragility curves for masonry buildings based on stochastic nonlinear analyses. "Engineering Structures 32, no. 5 (2010): 1312-1323.

[2] Shinozuka, Masanobu, Maria Q. Feng, Jongheon Lee, and Toshihiko Naganuma. "Statistical analysis of fragility curves." Journal of Engineering Mechanics 126, no. 12 (2000): 1224-1231.

[3] Kim, Sang-Hoon, and Masanobu Shinozuka. "Development of fragility curves of bridges retrofitted by column jacketing." Probabilistic Engineering Mechanics 19, no. 1 (2004): 105-112.

[4] Padgett, Jamie E., and Reginald DesRoches. "Methodology for the development of analytical fragility curves for retrofitted bridges." Earthquake Engineering and Structural Dynamics 37, no. 8 (2008): 1157-1174.

[5] Ichii, Koji. "Fragility curves for gravity-type quay walls based on effective stress analyses." 13th WCEE, Vancouver, BC (2004).

[6] Karim, Kazi Rezaul, and Fumio Yamazaki. "Effect of isolation on fragility curves of highway bridges based on simplified approach." Soil Dynamics and Earthquake Engineering 27, no. 5 (2007): 414-426.

[7] Ellingwood, Bruce, and Paulos B. Tekie. "Fragility analysis of concrete gravity dams." Journal of infrastructure systems 7, no. 2 (2001): 41-48.

[8] Tekie, Paulos B., and Bruce R. Ellingwood. "Seismic fragility assessment of concrete gravity dams." Earthquake engineering \& structural dynamics 32, no. 14 (2003): 2221-2240.

[9] Alembagheri, Mohammad, and Mohsen Ghaemian. "Damage assessment of a concrete arch dam through nonlinear incremental dynamic analysis." Soil Dynamics and Earthquake Engineering 44 (2013): 127-137.

[10] Alembagheri, Mohammad, and Mohsen Ghaemian. "Incremental dynamic analysis of concrete gravity dams including base and lift joints." Earthquake Engineering and Engineering Vibration 12, no. 1 (2013): 119-134.

[11] Mirzabozorg, H., M. Varmazyari, and M. Ghaemian. "Dam-reservoir-massed foundation system and travelling wave along reservoir bottom." Soil Dynamics and Earthquake Engineering 30, no. 8 (2010): 746-756.

[12] Soong, Tsu T. Fundamentals of probability and statistics for engineers. John Wiley \& Sons, 2004. 